\title{
The polymorphic phase transformations in resorcinol at high pressure
}

\author{
S.E. Kichanov ${ }^{1}$, D.P. Kozlenko ${ }^{1}$, P. Bilski ${ }^{2}$, J. Wąsicki ${ }^{2}$, W.Nawrocik ${ }^{2}$, A.Medek ${ }^{3,4}$, B.C.Hancock ${ }^{3}$, \\ E.V. Lukin ${ }^{1}$, C. Lathe $^{5}$, L.S. Dubrovinsky ${ }^{6}$, and B.N. Savenko ${ }^{1}$ \\ ${ }^{1}$ Frank Laboratory of Neutron Physics, JINR, 141980 Dubna, Moscow Region, Russia \\ ${ }^{2}$ Faculty of Physics, A.Mickiewicz University, Umultowska 85, 61-614 Poznań, Poland \\ ${ }^{3}$ Pfizer Inc., Eastern Point Road, Groton, CT 06340, USA \\ ${ }^{4}$ Vertex Pharmaceuticals, 130 Waverly St, Cambridge, USA \\ ${ }^{5}$ Helmholtz Centre Potsdam, Telegrafenberg, 14407 Potsdam, Germany \\ ${ }^{6}$ Bayerisches Geoinstitute, University Bayreuth, D-95440 Bayreuth, Germany
}

\begin{abstract}
Measurements of spin-lattice relaxation time $\mathrm{T}_{1}$ for resorcinol have been made by the proton NMR technique using the saturation method in the temperature range $280-380 \mathrm{~K}$ and pressure up to $800 \mathrm{MPa}$. The pressure-induced $\alpha-\beta$ transition evolved through two phase coexistence range was observed. The crystal structure and vibrational spectra of the resorcinol have also been studied by means of X-ray diffraction and Raman spectroscopy at pressures up to $19 \mathrm{GPa}$ in temperature range $290-380$ K. In experiments with a rapid pressurization rate, suppression of $\alpha-\beta$ polymorphic transition in resorcinol occurs. In experiments with a slow pressurization rate, two structural phase transitions, between orthorhombic $\alpha$ and $\beta$ phases at $P=0.4 \mathrm{GPa}$ and from $\beta$ to another orthorhombic $\gamma$ phase at $P=5.6 \mathrm{GPa}$, were observed. At pressures above $12.5 \mathrm{GPa}$, a gradual transformation to the amorphous phase was revealed. The lattice parameters, unit cell volumes and vibration modes as functions of pressure and temperature were obtained for the different polymorphic modifications of resorcinol.
\end{abstract}

Keywords: Phase transition, X-ray diffraction, High pressure, Raman spectroscopy

Corresponding author: S.E. Kichanov (e-mail: ekich@nf.jinr.ru). 


\section{Introduction}

Resorcinol $\mathrm{C}_{6} \mathrm{H}_{4}(\mathrm{OH})_{2}$ belongs to the group of phenols and it is a model organic compound which demonstrates a rich variety of interesting physical phenomena, such as polymorphic phase transitions [1]; pyroelectric and piezoelectric phenomena [2]. Besides, resorcinol has a wide range of applications in chemical technologies and pharmacology [3, 4].

At ambient pressure, resorcinol is known to exist in two phases, $\alpha$ and $\beta$ [5-9]. The ambient temperature $\alpha$ phase has an orthorhombic structure of Pna2 $2_{1}$ symmetry, as determined by X-ray and neutron diffraction [5-7]. A transition to the $\beta$ phase occurs on heating [5, 6] and transition temperature strongly affected by heating rate [8]. The $\beta$ phase has also the orthorhombic Pna $2_{1}$ symmetry, but it is drastically different from the $\alpha$ phase by a molecular arrangement and geometry of hydrogen bonds [9]. The $\alpha-\beta$ transition was also observed on compression of resorcinol at $P \sim 0.5$ $\mathrm{GPa}[8,10-12]$.

In Raman scattering studies [11] amorphization of resorcinol was reported at $P \sim 4 \mathrm{GPa}$, indicating breakdown of translational and orientational long range correlations between molecules. In contrast, subsequent Raman scattering studies [12] revealed an appearance of the new crystalline $\gamma$ phase of resorcinol at pressures above 5.6 GPa. Moreover, a rapid pressurization of resorcinol was found to lead to a suppression of the $\alpha-\beta$ transition and appending of new crystalline $\delta$ phase above 3 GPa [12]. The crystal structures of $\gamma$ and $\delta$ phases of resorcinol remain unexplored.

The recent studies of resorcinol [7-12] clearly demonstrate that pressure-induced polymorphic phase transitions in resorcinol are quite complex and require further elucidation. Moreover, heating or pressurization rate [12], thermal "history" or purity of the sample strongly affects the sequence of polymorphic phase transitions. In addition, most high pressure studies were characterized by Raman scattering method, while high pressure behaviour of crystal structure of resorcinol remain unexplored.

In order to study polymorphic phase transitions in more detail than previously, we have prepared a study of crystal structure, hydrogen dynamics and vibrational spectra of resorcinol by means of energy dispersive, angle dispersive X-ray diffraction, NMR and Raman spectroscopy at high pressures up to $19 \mathrm{GPa}$ and elevated temperatures up to $380 \mathrm{~K}$. 


\section{Experimental}

Resorcinol was obtained from Sigma Chemical Co., purity $99 \%$ and used as received.

The proton spin-lattice relaxation time $\mathrm{T}_{1}{ }^{\mathrm{H}}$ was measured as a function of temperature by a pulse spectrometer working at $58.9 \mathrm{MHz}$ in the Radiospectroscopy Laboratory at the Physics Faculty of A. Mickiewicz University [13]. The measurements were prepared by using the saturation recovery method. For pressure generation the U-11 helium gas compressor with beryllium-copper high-pressure set-up was used. The long spin-lattice relaxation time $\mathrm{T}_{1}$ raised difficulties in quality and rapidity measurements of P-T diagram. For faster measurement, we have applied the saturation method with a constant value of time interval $200 \mathrm{~s}$ between the end of the saturating series and the probing pulse. The FID (Free Induction Decay) amplitude for a polycrystalline sample was measured under hydrostatic pressure up to $800 \mathrm{MPa}$ in the temperature range from $280 \mathrm{~K}$ to $380 \mathrm{~K}$. The pressurisation and heating rate in experiments was $10-20{\mathrm{MPa} \times \mathrm{min}^{-1}}^{-1}$ and $2 \mathrm{~K} \times \mathrm{min}^{-1}$, respectively.

The X-ray diffraction experiments at high pressures were carried out using the multianvil X-ray system MAX80 [14]. The cubic boron-epoxy chamber with sample container was compressed by six tungsten carbide anvils in a large hydraulic press. The sample was placed in the cylindrical boron nitride container with an internal diameter of $1 \mathrm{~mm}$. The upper half was filled with the sample, the lower half contained sodium chloride powder for pressure calibration. The sample temperature was raised by an internal graphite heater and controlled by thermocouples. Diffraction patterns were recorded in an energy dispersive mode using white synchrotron X-rays from the storage ring DORISIII. The ring operated at $4.5 \mathrm{GeV}$ and a positron current of $80-150 \mathrm{~mA}$. The incident X-ray beam was collimated to $100 \times 100 \mu \mathrm{m}$ with a divergence smaller than $0.3 \mathrm{mrad}$. Spectra were recorded by a Ge solid-state detector with a resolution of $155 \mathrm{eV}$ at $5.9 \mathrm{keV}$ and $500 \mathrm{eV}$ at $122 \mathrm{keV}$ resulting in a resolution of diffraction patterns of $\Delta d / d \approx 1 \%$. The Bragg angle $2 \theta$ was fixed at $9.093^{\circ}$, counting times for each diffraction pattern were about $5 \mathrm{~min}$. The pressurisation and heating rate in experiments was 200-300 $\mathrm{MPa} \times \mathrm{min}^{-1}$ and $30 \mathrm{~K} \times \mathrm{min}^{-1}$, respectively. 
The angle-dispersive X-ray diffraction patterns at ambient temperature and pressures up to 19 GPa were measured at the system consisting of a high-brilliance FRD rotating anode generator (Mo $\mathrm{K}_{\alpha}$ radiation with $\lambda=0.7115 \AA$ ) FluxMax focusing optics, and Bruker APEX CCD area detector [15]. The two-dimensional XRD images were converted to conventional one-dimensional diffraction patterns using the FIT2D program [16].

Raman spectra at ambient temperature and pressures up to $19.0 \mathrm{GPa}$ were collected using LabRam spectrometer (NeHe excitation laser) with wavelength $632.8 \mathrm{~nm}$, grating 1800, confocal hole $1100 \mu \mathrm{m}, \mathrm{x} 50$ objective.

The angle dispersive X-rays diffraction and Raman spectroscopy experiments have been prepared with the same four-pin type diamond anvil cell [15] so the pressure points and experiment condition for both methods was identical. The pressure was determined by the ruby fluorescence technique. The resorcinol sample is very soft and it reacts with most of the commonly used pressure transmitting substances. As a result, experiments were prepared without pressure transmitting medium.

The refinement of powder diffraction patterns were made by means of the VMRIA [17] and Fullprof [18] program.

\section{Results and discussion}

\subsection{NMR spectroscopy}

The temperature dependence of the FID amplitude of resorcinol measured at ambient pressure exhibits a sharp increase at $T=363 \mathrm{~K}$, associated with the change of the spin relaxation time $\mathrm{T}_{1}$ due to the $\alpha-\beta$ phase transition (fig. 1). The pressure dependences of the FID amplitudes of resorcinol at selected temperatures are shown in fig. 2. They exhibit two characteristic breaks at separate pressures, implying that the $\alpha$ - $\beta$ phase transition occurs through the phase coexistence range upon compression. With temperature decrease from 360 to $280 \mathrm{~K}$ the phase coexistence range was somewhat expanded. Without taking of consideration of phase transition kinetic (see Discussion section below) we can build the quasiequilibrium "phase pattern" for resorcinol in the $0-800 \mathrm{MPa}$ pressure and $280-380 \mathrm{~K}$ temperature ranges constructed from the NMR data obtained with the pressurisation and heating rates 


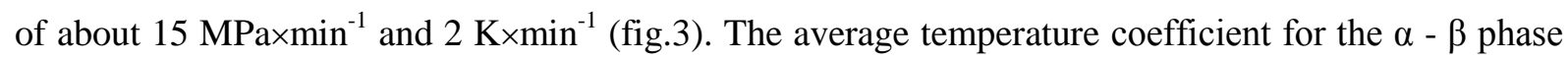
transition pressure was found to be negative, $(d P / d T)_{\alpha-\beta}=-2.4(2) \mathrm{MPa} / \mathrm{K}$. It is comparable with one obtained previously, $-1.67 \mathrm{MPa} / \mathrm{K}[8]$.

\subsection{Energy-dispersive X-Ray diffraction}

The energy dispersive X-ray diffraction patterns of resorcinol measured at different pressures and temperatures are shown in fig. 4. At ambient conditions the orthorhombic $\alpha$ phase with the space group Pna2 ${ }_{1}$ was evidenced. The calculated lattice parameters were $a=10.562(7) \AA, b=9.563(6) \AA$ and $c=5.683(7) \AA$, in agreement with previous results $[6,7]$. At ambient temperature, no phase transitions were observed on compression up to $3.2 \mathrm{GPa}$. The apparent discrepancy between this observation and the NMR data as well as when compared to previous experiments [5-9] can be explained by faster heating rate of $\sim 30 \mathrm{~K} \times \mathrm{min}^{-1}[8,12]$ in present diffraction experiment, leading to a stability of the $\alpha$ phase in more extended temperature range. The lattice parameters and unit cell volume of $\alpha$-phases of resorcinol as functions of pressure are shown in fig. 5. The volume compressibility data were fitted by the Birch-Murnaghan equation of state [19]:

$$
P=3 / 2 B_{0}\left(x^{-7 / 3}-x^{-5 / 3}\right)\left[1+3 / 4\left(B^{\prime}-4\right)\left(x^{-2 / 3}-1\right)\right]
$$

where $x=V / V_{0}$ is the relative volume change, $V_{0}$ is the unit cell volume at $P=0 \mathrm{GPa} ; B_{0}$ and $B^{\prime}$ are the bulk modulus $B_{0}=-V(d P / d V)_{T}$ and its pressure derivative $B^{\prime}=\left(d B_{0} / d P\right)_{T}$. The value $B_{0}=11(3) \mathrm{GPa}$ was calculated with a fixed $B^{\prime}=4$. The compressibilities $\quad k_{i}=-\left(1 / a_{i 0}\right)\left(d a_{i} / d P\right)_{T}\left(a_{i}=a, b, c\right)$ of unit cell parameters for the $\alpha$-phase, calculated on the one-dimensional Murnaghan equation of state [20], are $k_{a}=0.030(7), k_{b}=0.043(4), k_{c}=0.033(5) \mathrm{GPa}^{-1}$, respectively.

At small pressure value $P=0.09 \mathrm{GPa}$ the $\alpha-\beta$ phase transition occurs on heating at $T=358 \mathrm{~K}$ (fig. 4). In the temperature range $358-375 \mathrm{~K}$ both phases coexist, and the pure $\beta$ phase with the Pna2 is observed above $375 \mathrm{~K}$. The values of lattice parameters, calculated at $T=375 \mathrm{~K}, a=7.945(7) \AA$, $b=12.423(6) \AA$ and $c=5.556(7) \AA$, are in agreement with previous studies [7,9]. The temperature dependences of lattice parameters and unit cell volume are shown at fig. 6 . The thermal volume 
expansion coefficient $\left.\alpha=1 / V^{(d V / d T}\right)_{p}$ for the resorcinol was calculated to be $1.6(3) \times 10^{-4} \mathrm{~K}^{-1}$ for the $\alpha$ phase at ambient pressure and $1.0(4) \times 10^{-4} \mathrm{~K}^{-1}$ for the $\beta$ phase at $P=0.09 \mathrm{GPa}$.

\subsection{Angle dispersive X-ray diffraction}

Due to limited pressure range up to $4 \mathrm{GPa}$, available with the high pressure setup for energy dispersive X-ray diffraction, additional angle dispersive X-ray diffraction experiments with diamond anvil cell were prepared in the extended pressure range up to $20 \mathrm{GPa}$.

X-ray diffraction patterns of resorcinol measured at different pressures and ambient temperature are shown in fig. 7. At $P \sim 0.4 \mathrm{GPa}$ the $\alpha-\beta$ phase transition was detected (fig. 4).

At $P=5.6 \mathrm{GPa}$ changes in X-ray diffraction patterns were observed (fig. 7), providing evidence for the structural phase transition. The newly appeared high pressure phase is likely to be the $\gamma$-phase in terms of the previous Raman spectroscopy experiments [12]. The diffraction peaks of the $\gamma$-phase can be properly indexed within the orthorhombic structural model of Pnna symmetry. The unit cell parameters at $P=5.6 \mathrm{GPa}$ are $a=7.3346 \AA, b=11.4861(7) \AA, c=9.246(5) \AA$.

The relationship between initial parameters $a_{\beta}, b_{\beta}$ and $c_{\beta}$ of $\beta$-phase and lattice parameters $a_{\gamma}, b_{\gamma}$ and $c_{\gamma}$ of $\gamma$-phase is $a_{\gamma} \approx a_{\beta}, b_{\gamma} \approx b_{\beta}$ and $c_{\gamma} \approx 2 \times c_{\beta}$. One should note that the crystal structure of the $\gamma$ phase can be described as a superstructure with a doubled $c$ implying a possible reorientation of resorcinol molecules in this polymorphic phase.

The lattice parameters and unit cell volume of different phases of resorcinol as functions of pressure are shown in fig. 8 . The linear compressibilities $k_{i}=-\left(1 / a_{i 0}\right)\left(d a_{i} / d P\right)_{T}\left(a_{i}=a, b, c\right)$ of unit cell parameters are $k_{a}=0.015(7), k_{b}=0.018(9), k_{c}=0.020(5) \mathrm{GPa}^{-1}$ for $\beta$-phase of resorcinol and $k_{a}=$ $0.0092(7), k_{b}=0.0072(9), k_{c}=0.0064(5) \mathrm{GPa}^{-1}$ for $\gamma$-phase of resorcinol. The volume compressibility data were fitted by the Birch-Murnaghan equation of state (1). The values $B_{0}=11(3) \mathrm{GPa}$ and $B_{0}=$ 12(3) GPa were calculated for $\beta$-phase and $\gamma$-phase, respectively, with a fixed $B^{\prime}=4$.

With a further pressure increase, at $P>11.2 \mathrm{GPa}$ the broad diffusion halo was observed (Fig. 7). This fact indicates a start of transition to amorphous phase as it was found in previous experiments 
$[11,12]$. As the pressure was increased the fraction of amorphous phase increased and at $P=17.5(2)$

GPa the pure amorphous phase was observed.

\subsection{High pressure Raman spectroscopy}

The Raman spectra of resorcinol obtained at different pressures are shown in Fig. 9. The tentative assignment of band frequencies was based on previous Raman spectroscopy data $[11,21]$ and listed in Table 1. For a description of the vibrational modes of the resorcinol molecule we used notations from Ref [21].

At $P \sim 0.4 \mathrm{GPa}$, an appearance of two Raman peaks at around $1150 \mathrm{~cm}^{-1}$, corresponding to inplane $\mathrm{C}-\mathrm{H}$ bending modes, and disappearance of the $\mathrm{C}-\mathrm{H}$ stretching mode peak located around 3060 cm-1, were observed (fig. 9a-e), indicating a pressure-induced polymorphic $\alpha-\beta$ transition in resorcinol $[11,12]$.

At $P=5.6 \mathrm{GPa}$ an appearance of two additional Raman peaks at $1080 \mathrm{~cm}^{-1}$, in the in-plane $\mathrm{C}-\mathrm{H}$ bending modes region, as well as broadening of some Raman peaks were observed, reflecting another structural transition to the $\gamma$-phase (Fig. 9a-c) [12]. At $P>12.4$ GPa a gradual broadening of Raman modes, followed by disappearance of the most of them at about $17.5 \mathrm{GPa}$, were observed (Fig. 9a-c). Above $P=17.5 \mathrm{GPa}$, only two weak modes, corresponding to free ring vibrations, were observed (fig. 9). Such a behavior corresponds to a gradual phase transition to the amorphous phase of the resorcinol. In the previous study the amorphous phase of resorcinol was found to appear at $P \sim 11 \mathrm{GPa}$ [12], which is in good agreement with our result $P \sim 12.4 \mathrm{GPa}$.

Figure 10a-c shows the pressure dependence of selected vibrational modes in different phases of resorcinol. Noticeable changes of pressure coefficients $d v_{i} / d P$ at the $\beta-\gamma$ phase transition were observed for frequencies of the stretching $\mathrm{C}-\mathrm{C}$ and $\mathrm{C}-\mathrm{H}$ modes while behavior of ring bending modes is less affected. 
From experimental data one can calculate the mode Gruneisen parameters [22] as $\gamma_{i}=d \ln v_{i} / d \ln V$ $=\left(B_{0} / v_{i}\right)\left(d v_{i} / d P\right)$, where $v_{i}$ is the mode frequency, $B_{0}=-V(d P / d V)_{T}-$ bulk modulus and $V-$ unit cell volume. The maximum values of pressure coefficients $d v_{i} / d P \sim 9 \mathrm{~cm}^{-1} / \mathrm{GPa}$ were found for lattice modes, in agreement with previous studies [12]. Such values are typical for molecular solids [23]. The obtained $\gamma_{i}$ values of vibrational modes for $\beta$-, $\gamma$-phases and ring vibrational modes of amorphous phase are listed in Table 1. In calculations the bulk modulus values determined from structural data (see previous sections) were used. The values $\gamma_{i}<0.1$ are characteristic for internal modes and their low values compared with lattice modes $\left(\gamma_{i}>0.5\right)$, indicate weak modification of intra-molecular bonds upon application of high pressure.

\section{Discussion.}

Our results, obtained by different experimental techniques, demonstrate that phase transition in resorcinol has complex character of elaboration and significantly affected by the rates of the temperature and pressure change. It is known that the $\alpha-\beta$ phase transition in resorcinol results in significant reconstruction of hydrogen bonding geometry in the crystal structure [9]. In the accurate investigation of this transition by means of fluorescence-lifetime measurements some precursors of polymorphic transition with temperature variation were found [24].

In order to explain the observed complex elaboration of the phase transition in resorcinol on the rate of variation of thermodynamic parameters, one needs to consider the kinetics of the phase transitions. Let us consider the model $[25,26]$, where the polymorphic transition is interpreted as coming via consecutive stages, forming of new phase impurity in initial phase (nucleation), following growing of impurity fraction and total disappearing of initial phase on finish. The growing stage corresponds to mixed (phase separated) state and time unstable. The similar characters of polymorphic transition with mixed state were observed in sulfanilamide [27], $\mathrm{KCl}$ [28] and other compounds [26].

So, in resorcinol the $\alpha-\beta$ transition can be presented as sequence $\alpha$-phase $\rightarrow \alpha+\beta \rightarrow \beta-$ phase. The time dependent kinetics of such complex transitions is described by Avrami relationship [26, 29] assuming that the transition proceeds by a nucleation-and-growth mechanism [28]:

$$
X(t)=1-\exp (-k t)^{\mathrm{n}},
$$


were $X$ is the fraction of new phase, $t$ - the time, $k \sim 1 / \tau$, - function [28] depending on temperature, pressure, grain size or shear stress, $\tau$ - life time of mixed state [28]; $n$-parameter, characterizing transition processes such as nucleation and growing topology.

The NMR spectroscopy and energy-dispersive X-rays diffraction experimental results directly indicate the existing of mixed state in resorcinol at $\alpha-\beta$ transition. In concordance with (2) the time dependence of this mixed state should be observed. We prepared additional NMR spectroscopy experiments. The FID amplitude as function of pressure was measured immediately after heating up to $315 \mathrm{~K}$ and after waiting time of $40 \mathrm{~min}$. The resulting curves are shown at Fig. 11. The $\alpha-\beta$ transition pressure is reduced from about 200 to $175 \mathrm{MPa}$ with time waiting and the shape of the FID curve somewhat changes. At $P=200 \mathrm{MPa}$ the FID amplitude $A_{\mathrm{FID}}$ associated with $\beta$-phase fraction was $\sim 318$ and $\sim 393$ a.u. for immediate and delayed measurements, respectively. We can assume that at $A_{\mathrm{FID}}=512$ a.u. transition into $\beta$-phase is completed and the "life time" [28] of the mixed $\alpha-\beta$ state in resorcinol at temperature $T=315 \mathrm{~K}$ can be estimated using Eq. (2), $\tau \sim 120 \mathrm{~min}$.

The long "life time" $\tau \sim 2 \mathrm{~h}$ of mixed state of resorcinol can explain differences in results obtained by means of NMR spectroscopy and energy-dispersive X-rays diffraction (see Section 3.1 and 3.2). The exposition time in diffraction experiment was $3 \mathrm{~min}$, which are shorter than calculated $\tau$. In this case the mixed phase was formed at pressure but the fraction of $\beta$-phase was small and undetectable. The additional heating urged $\beta$-phase formation in resorcinol. The suppression of $\alpha-\beta$ transition in resorcinol is a result of influence of this factor. In contrast, the long experimental time in our NMR experiments $(\sim 3 \mathrm{~h})$ and $\mathrm{X}$-rays diffraction with DAC $(\sim 1 \mathrm{~h})$ affect the $\beta$-phase observed. The particular case of fast experiments is compression with rapid pressurization [12], which leads to suppression of $\alpha-\beta$ transition in resorcinol. On basis of our data, the pressure step at rapid pressurization should be bigger than mixed state pressure range at room temperature. The simple calculation has yielded it as $\Delta P>0.5 \mathrm{GPa}$.

The crystal structure of the $\gamma$-phase can be described as a superstructure with respect to $\beta$-phase, implying a possible reorientation of resorcinol molecules. The amorphization of resorcinol evolves through mixed state of $\gamma$ - and amorphous phases. The pressure range of existence of this mixed state is 
up to $\sim 7 \mathrm{GPa}$. The kinetic or mechanism of transition into amorphous phase remain unclear. Our estimations show that the "life time" for such a mixed state, $\tau>4000 \mathrm{~min}$, is considerably large in comparison with one for the $\alpha-\beta$, making the experimental study of the transition from $\gamma$ - to amorphous phase complicated.

\section{Conclusion}

In the present work high pressure and temperature effects on the crystal structure and vibrational spectra of resorcinol have been studied. Three high pressure polymorphic transitions were observed. The $\alpha-\beta$ phase transition was evolved via the mixed state. In the case when characteristic experimental times were much shorter than "life-time" of mixed state $\tau \sim 120 \mathrm{~min}$, describing the transition kinetics, the phase transition was not detectable. In experiments with long exposition times, the $\alpha-\beta$ phase was observed. Another phase transition to $\gamma$-phase was observed at $P \sim 5 \mathrm{GPa}$. Upon further compression, the amorphization of resorcinol was found.

\section{Acknowledgements}

The work has been partially financed by RFBR Grant No 11-02-00416-a, state contract 02.740.11.0542, Federal programs "The priority activities in researches and developments of scientific-technological complex of Russia in 2007-2012" and "Research and scientific- educational personnel of innovation Russia in 2009-2013" and the Ministry of Science and Higher Education of Poland Grant No. 202032937. 


\section{References.}

[1] J. Bernstein, Polymorphism in Molecular Crystals, Oxford University Press, 2002.

[2] J.M. Robertson, Proc. Roy. Soc. A, 157 (1936) 79.

[3] R. B. Durairaj, Resorcinol: Chemistry, Technology and Applications, Springer, 2005.

[4] H. Dressler, Resorcinol: Its Uses and Derivatives, Springer (1995).

[5] J.M. Robertson, A.R. Ubbelhode, Proc. Roy. Soc. A, 167 (1938) 122-135

[6] G.E. Bacon and N.A. Curry, Proc. R. Soc. Lon. A, 235 (1956) 552-559

[7] S.H. Dharma, V. Vijayakumar, S.K. Sikka, R. Chidambaram, Rapmana, 25 (1985) 75.

[8] Y. Ebisuzaki, L.H. Askari, A.M. Bryan, M.F. Nicol, J.Chem. Phys., 87(11) (1987) 6659-6664.

[9] G.E. Bacon, E.J. Lisher, Acta Crystallogr., B36 (1980) 1908.

[10] M. Yoshino, K. Takahashi, Y. Okuda, T. Yoshizawa, N. Fukushima, M. Naoki, J. Phys. Chem. A, 103 (1999) 2775

[11] S.K. Deb, M.A. Rekha, A.P. Roy, V.Vijayakumar, S.Meenakshi, B.K. Gudwal, Phys. Rev. B, 47 (1993) 11491-11494.

[12] R. Rao, T. Sakuntala, B.K. Godwal, Phys. Rev. B, 65 (2002) 054108.

[13] S. Lewicki, Z. Pajak, W. Porzuckowiak and J. Wasicki, Proc. 28th NMR Seminar (Krakow), Report 1717/PL (1995) p. 190.

[14] P. Zinn, J. Lauterjung, R. Wirth, Zeitschrift fur Kristallographie, 212 (1997) 691-698.

[15] N.A. Dubrovinskaia and L.S. Dubrovinsky Rev.Sci.Instrum.,74 (2003) 3433.

[16] A.P. Hammersley, S.O. Svensson, M. Hanfland, A.N. Fitchand, D. Hausermann, High Press. Res., 14 (1996) 235.

[17] V.B. Zlokazov, in thesis book of «IV Workshop on investigations at the IBR-2 pulsed reactor», Russia, Dubna, (2005) p.75.

[18] J. Rodriguez-Carvajal, Physica B, 192 (1993) 55.

[19] F. J. Birch, J. Geophys. Res., 91 (1986) 4949.

[20] V.L. Solozhenko, E. G. Solozhenko, C. Lathe, Solid State Comm., 137 (2006) 533-535.

[21] G.N.R. Tripaphi, J.Chem.Phys., 74 (1980) 250-255

[22] E.Grüneisen, Handbuch der Physik, Springer Verlag, Berlin, v.1, 1926. 
[23] J.M.Besson, M.M.Thiery and Ph.Pruzan, in Molecular Systems Under Pressure, edited R. Pucci and G. Piccito, North-Holland, Amsterdam, p. 341 (1991)

[24] T.Shigenary, E.Kojima, Y.Ino, K.Abe, Phys.Rev.Lett., 66 (1991) 2112.

[25] A.K. Singh, Bull.Matter.Sci, 5 (1983) 219-230.

[26] N. V. C. Shekar and K. G. Rajan, Bull.Matter.Sci, 24 (2001) 1-21.

[27] A. K. Sheridan and J. Anwar, Chem. Mater., 8 (1996) 1042.

[28] R. Dassler, High Temp. High Press., 20 (1988) 661.

[29] M. Avrami, J. Chem. Phys., 9 (1941) 177. 
Table 1. The tentative assignment and wavenumbers $\left(\mathrm{cm}^{-1}\right)$ of the fundamental Raman active bands of resorcinol at room temperature and selected pressures. Abbreviations: $v$ - stretching; $\beta$ - bending inplane; $\phi$ - bending out-of-plane, br -broad line. The calculated Gruneisen parameters $\gamma_{i}$ for $\beta$-phase and $\gamma$-phase of resorcinol are listed.

\begin{tabular}{|c|c|c|c|c|c|c|}
\hline $\begin{array}{c}\text { Tentative } \\
\text { assignment }\end{array}$ & $\begin{array}{c}P=0 \text { GPa } \\
\alpha \text {-phase }\end{array}$ & $\begin{array}{c}P=0.7 \text { GPa } \\
\beta \text {-phase }\end{array}$ & $\gamma_{i}$ & $\begin{array}{c}P=5.6 \text { GPa } \\
\gamma \text {-phase }\end{array}$ & $\gamma_{i}$ & $\begin{array}{c}P=19.0 \mathrm{GPa} \\
\text { amorphous }\end{array}$ \\
\hline $\begin{array}{l}v \mathrm{CH} \\
v \mathrm{CH} \\
v \mathrm{CH}\end{array}$ & $\begin{array}{l}3075.4(4) \\
3060.9(3) \\
3048.9(3)\end{array}$ & $\begin{array}{l}3073.1(4) \\
3056.1(3) \\
3045.1(3)\end{array}$ & $\begin{array}{l}0.021(2) \\
0.018(2) \\
0.012(3)\end{array}$ & $\begin{array}{l}\text { 3072(3) } \boldsymbol{b r} \\
\text { 3040(2) } \boldsymbol{b r}\end{array}$ & $\begin{array}{l}0,013(7) \\
0,023(5)\end{array}$ & \\
\hline $\begin{array}{l}\text { vCC } \\
\text { vCC } \\
\text { vCC }\end{array}$ & $\begin{array}{l}1611.9(1) \\
1604.1(1)\end{array}$ & $\begin{array}{l}1619.2(1) \\
1607.0(1)\end{array}$ & $\begin{array}{l}0,022(2) \\
0,016(3)\end{array}$ & $\begin{array}{l}1640.2(3) \\
1624.2(2) \\
1610.2(3)\end{array}$ & $\begin{array}{l}0,016(4) \\
0,017(5) \\
0,016(4)\end{array}$ & \\
\hline $\begin{array}{l}\beta \mathrm{CH} \\
\beta \mathrm{CH} \\
\beta \mathrm{CH} \\
\beta \mathrm{CH} \\
\beta \mathrm{CH} \\
\beta \mathrm{CH}\end{array}$ & $1088.9(1)$ & $\begin{array}{l}1160.2(5) \\
1148.3(4)\end{array}$ & $\begin{array}{l}0,023(8) \\
0,024(9) \\
0,019(4)\end{array}$ & $\begin{array}{l}1181(3) \\
1168.3(8) \\
1156(1) \\
1104.2(4) \\
1093.0(1) \\
1081.7(3)\end{array}$ & $\begin{array}{l}\sim 0 \\
\sim 0 \\
0.03(6) \\
\sim 0 \\
0,025(4) \\
0,021(4)\end{array}$ & \\
\hline ring1 & $993.3(2)$ & $998.5(2)$ & $0,021(3)$ & $1011.7(4)$ & $0,024(5)$ & $1040.8(5)$ \\
\hline ring2 & $744.6(2)$ & $740.9(2)$ & $0,021(4)$ & $\begin{array}{l}759.6(2) \\
620.3(1)\end{array}$ & $\begin{array}{l}0,035(7) \\
0,020(8)\end{array}$ & 793.3(3) \\
\hline $\begin{array}{l}\phi \mathrm{CC} \\
\phi \mathrm{CC}\end{array}$ & $\begin{array}{l}546.4(3) \\
541.4(2)\end{array}$ & $\begin{array}{l}540.5(3) \\
527.4(1)\end{array}$ & $\begin{array}{l}0,021(3) \\
0,019(7)\end{array}$ & $531.1(6)$ & $\begin{array}{l}\sim 0 \\
0.02(6)\end{array}$ & \\
\hline $\begin{array}{l}\phi \mathrm{CC} \\
\phi \mathrm{CC}\end{array}$ & $\begin{array}{l}533.4(1) \\
463.4(3)\end{array}$ & $\begin{array}{l}465.4(3) \\
460.2(2)\end{array}$ & $\begin{array}{l}0,024(6) \\
0,017(7)\end{array}$ & & & \\
\hline $\begin{array}{c}\text { overtone } \\
\text { overtone } \\
\text { lattice } \\
\text { lattice } \\
\text { lattice } \\
\text { lattice }\end{array}$ & $\begin{array}{l}257.4(3) \\
249.1(3)\end{array}$ & $\begin{array}{l}255.7(3) \\
247.1(3) \\
171.0(3) \\
126.4(2)\end{array}$ & $\begin{array}{l}0,517(9) \\
0,486(7) \\
0,626(7) \\
0,406(5)\end{array}$ & $\begin{array}{l}311.6(3) \\
290.7(6) \\
268.5(6) \\
237.5(3) \\
210.2(4) \\
190.7(4)\end{array}$ & $\begin{array}{l}0.52(6) \\
\sim 0.5 \\
0.45(9) \\
\sim 0.4 \\
0.69(4) \\
\sim 0.6\end{array}$ & \\
\hline
\end{tabular}




\section{Figure caption.}

Figure 1. The FID amplitude as a function of temperature for resorcinol at ambient pressure. The solid lines are linear interpolations of the experimental data.

Figure 2. The pressure dependence of the FID amplitude at temperature $\mathrm{T}=330$ and $310 \mathrm{~K}$ (a) and $\mathrm{T}=300$ and $280 \mathrm{~K}(\mathrm{~b})$. The solid lines are linear interpolations of the experimental data.

Figure 3. The "phase pattern" of resorcinol based on NMR experimental data with constant pressurization and heating rates.

Figure 4. The energy dispersive X-ray diffraction patterns of the resorcinol measured at ambient conditions, pressures $P=0.09 \mathrm{GPa}$ and temperature $\mathrm{T}=355$ and $375 \mathrm{~K}$ and $\mathrm{P}=3.2 \mathrm{GPa}$ at room temperature. All patterns processed by the profile matching method. Experimental points, calculated profiles and difference curve (for $P=3.2 \mathrm{GPa}$ ) are shown. The tick rows indicate the calculated diffraction peaks positions for $\alpha$-phase at ambient and high pressure conditions. The positions of addition peaks from $\mathrm{BN}$ container are marked.

Figure 5. The pressure dependencies of unit cell parameters (a) and relative unit cell volume (b) of the $\alpha$-phase of resorcinol. Solid lines represents fit on the basis of the one-dimensional Murnaghan and Birch-Murnaghan equation of state.

Figure 6. The temperature dependence of the lattice parameters (a) and unit cell volume (b) of $\alpha$-phase and $\beta$-phase of resorcinol at $P=0.09 \mathrm{GPa}$. The solid lines represent the linear fit of the experimental data. The «m» is marked phase coexistence temperature range.

Figure 7. X-ray diffraction patterns of resorcinol measured at pressures $0.4,5.6,16.4$ and 19.0 $\mathrm{GPa}$ and room temperature and processed by the profile matching method. Experimental points, calculated profiles and difference curve (for $P=5.6 \mathrm{GPa}$ ) are shown. The ticks indicate 
the calculated diffraction peaks positions for high pressure $\gamma$-phase (upper row) and low pressure $\beta$-phase (lower row). The positions of addition peaks from $\alpha$-phase impurity are marked.

Figure 8. a) The pressure dependencies of lattice parameters of the $\beta$-phase and high pressure $\gamma$-phase of resorcinol. Solid lines represent linear fits to the experimental data. b).The unit cell volume as function of pressure. The experimental data were fitted on the basis of the BirchMurnaghan equation of state.

Figure 9. The parts of Raman spectra of resorcinol, measured at $P=0,0.7,5.6,16.4$ and 19.0 GPa for $180-1200 \mathrm{~cm}^{-1}$ (a) and $3000-3200 \mathrm{~cm}^{-1}$ (b) regions. The enlarged parts for $500-690$ $\mathrm{cm}^{-1}$ (c), $1000-1200 \mathrm{~cm}^{-1}$ (d) and 1550-1750 $\mathrm{cm}^{-1}$ (e) regions. The broad Raman line from diamond anvils is marked as " $\mathrm{D}$ ".

Figure 10. a). Pressure dependence of C-H stretching modes of resorcinol. The estimated error bars are within symbol sizes. The solid lines are linear interpolations of the experimental data. b). Pressure dependence of $v(\mathrm{C}-\mathrm{C})$ stretching modes of resorcinol. The estimated error bars are within symbol sizes. The solid lines are linear interpolations of the experimental data.

c). Pressure dependence of in-plane and ring vibration modes of resorcinol. The estimated error bars are within symbol sizes. The solid lines are linear interpolations of the experimental data.

Figure 11. The pressure dependence of the FID amplitude at temperature $T=315 \mathrm{~K}$ measurement immediately and after $\sim 40$ min after heating. 


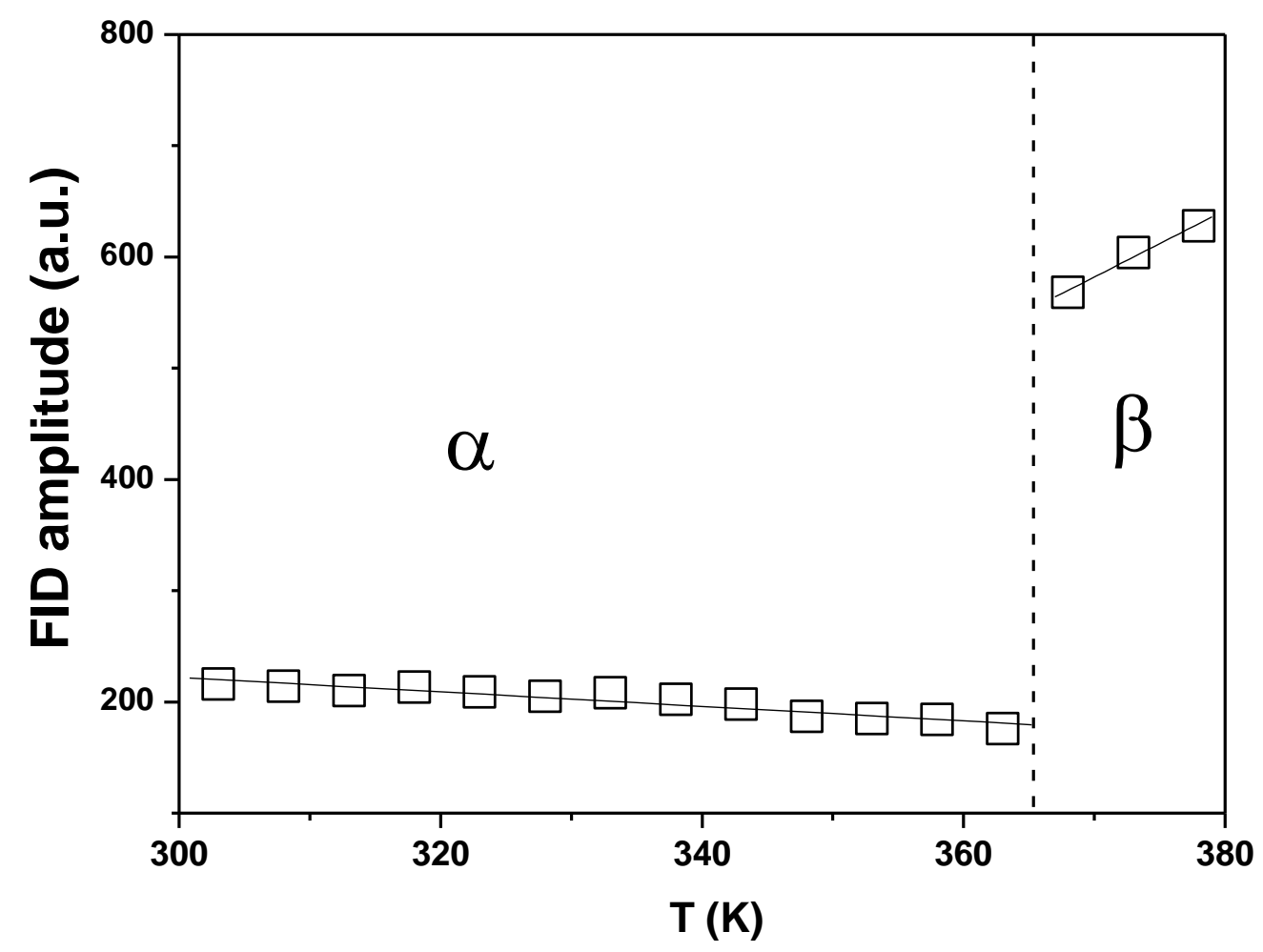

Figure 1. S.E. Kichanov, The polymorphic phase transformations in resorcinol at high pressure 

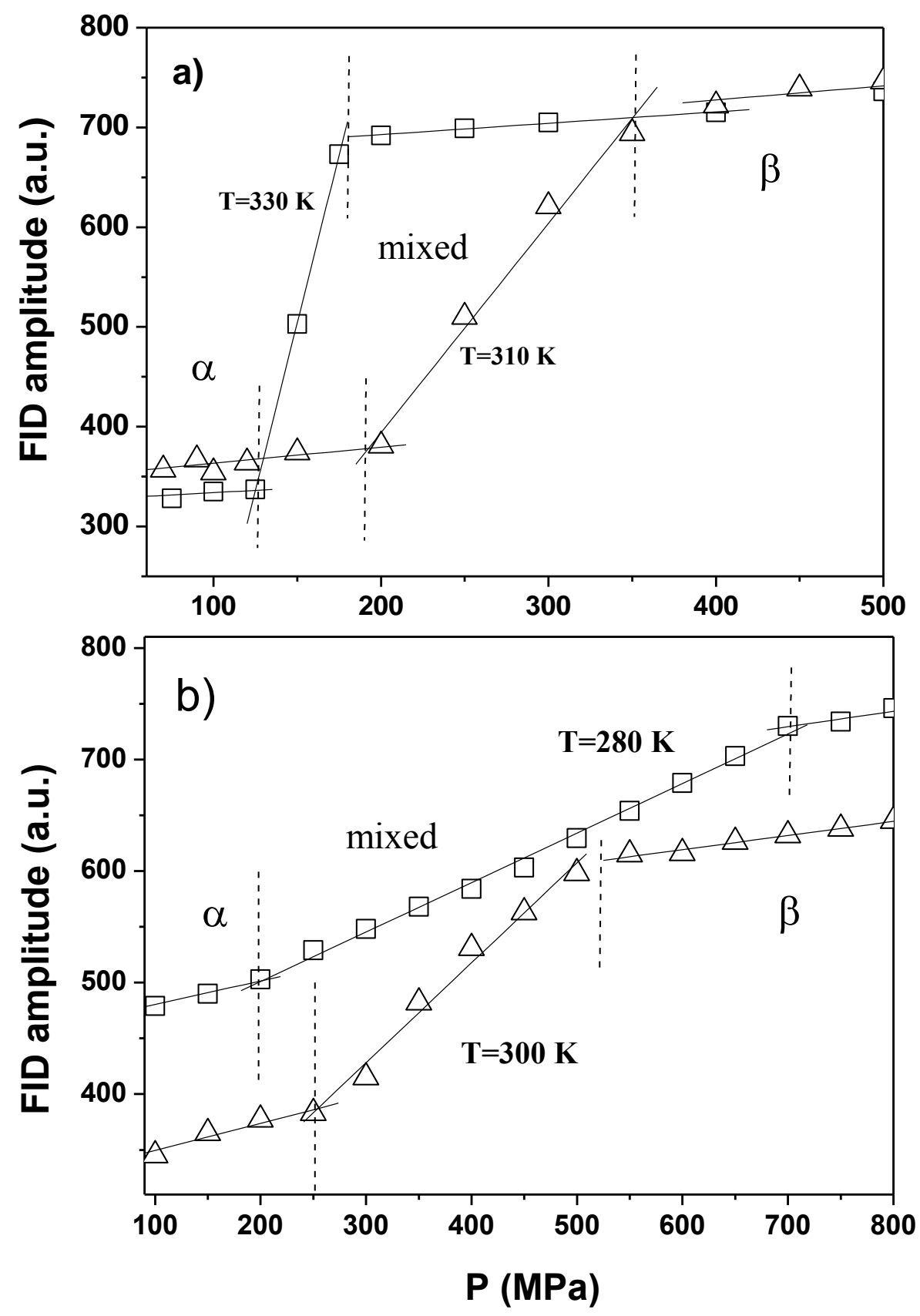

Figure 2. S.E. Kichanov, The polymorphic phase transformations in resorcinol at high pressure 


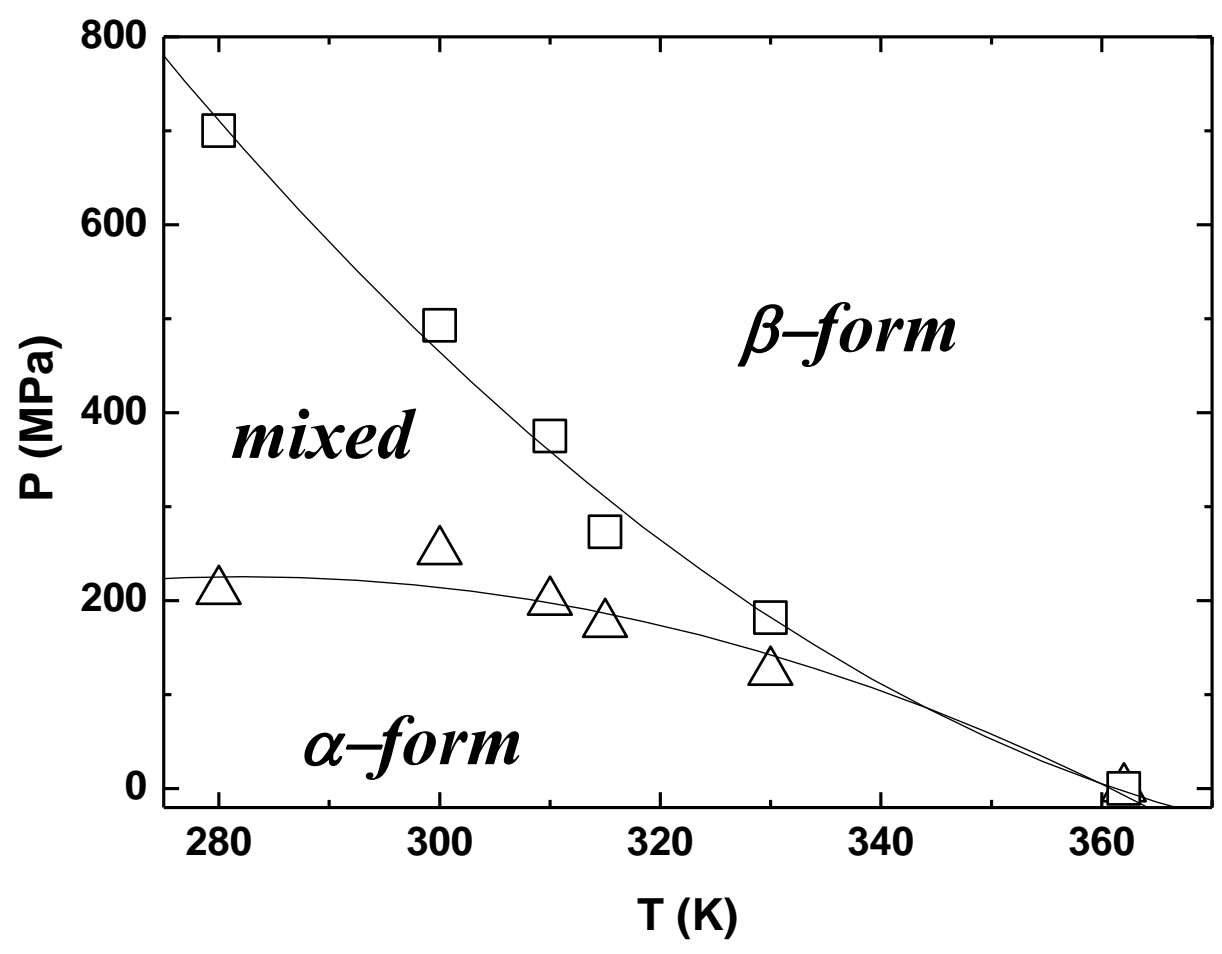

Figure 3. S.E. Kichanov, The polymorphic phase transformations in resorcinol at high pressure 


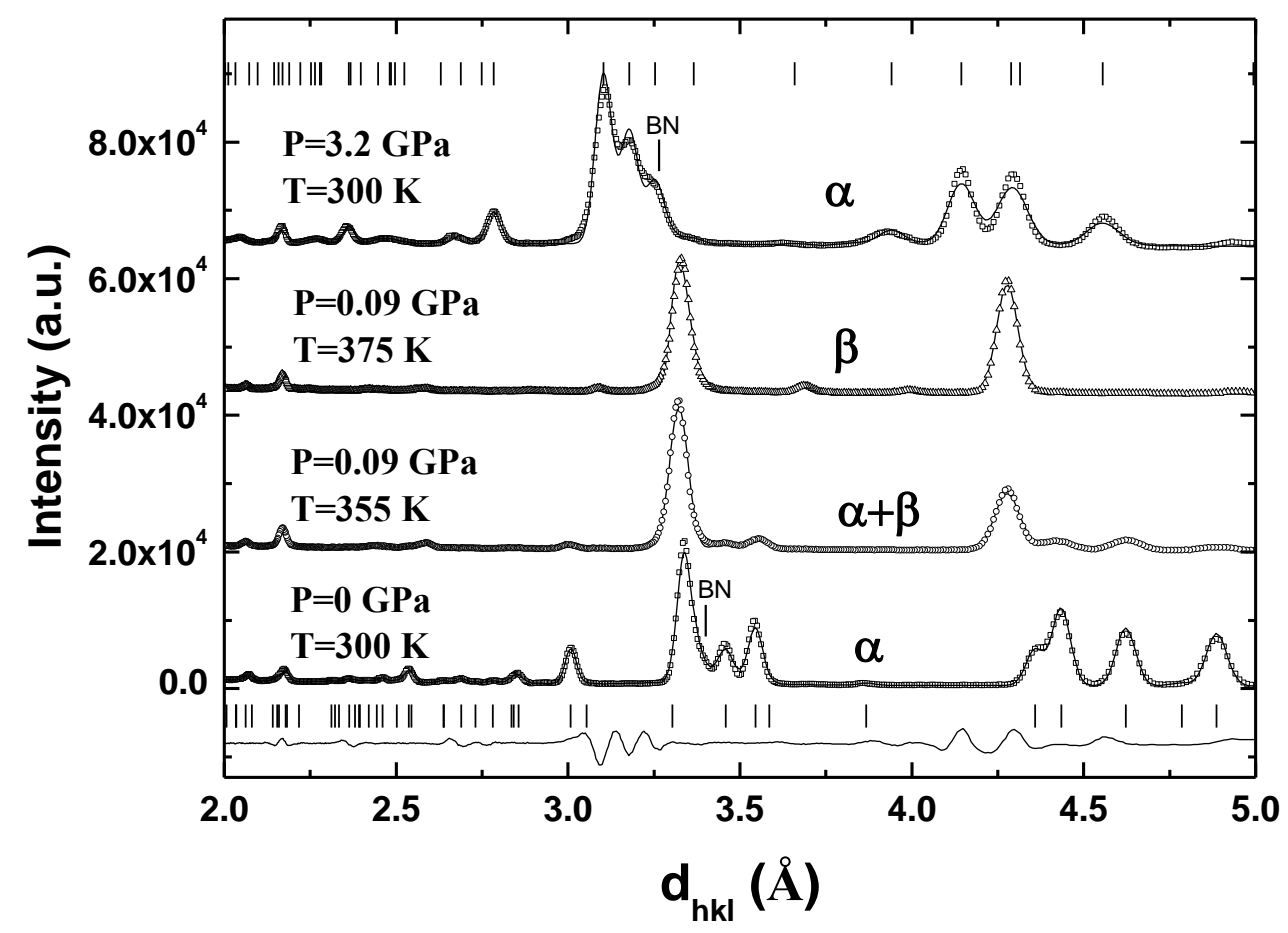

Figure 4. S.E. Kichanov, The polymorphic phase transformations in resorcinol at high pressure 


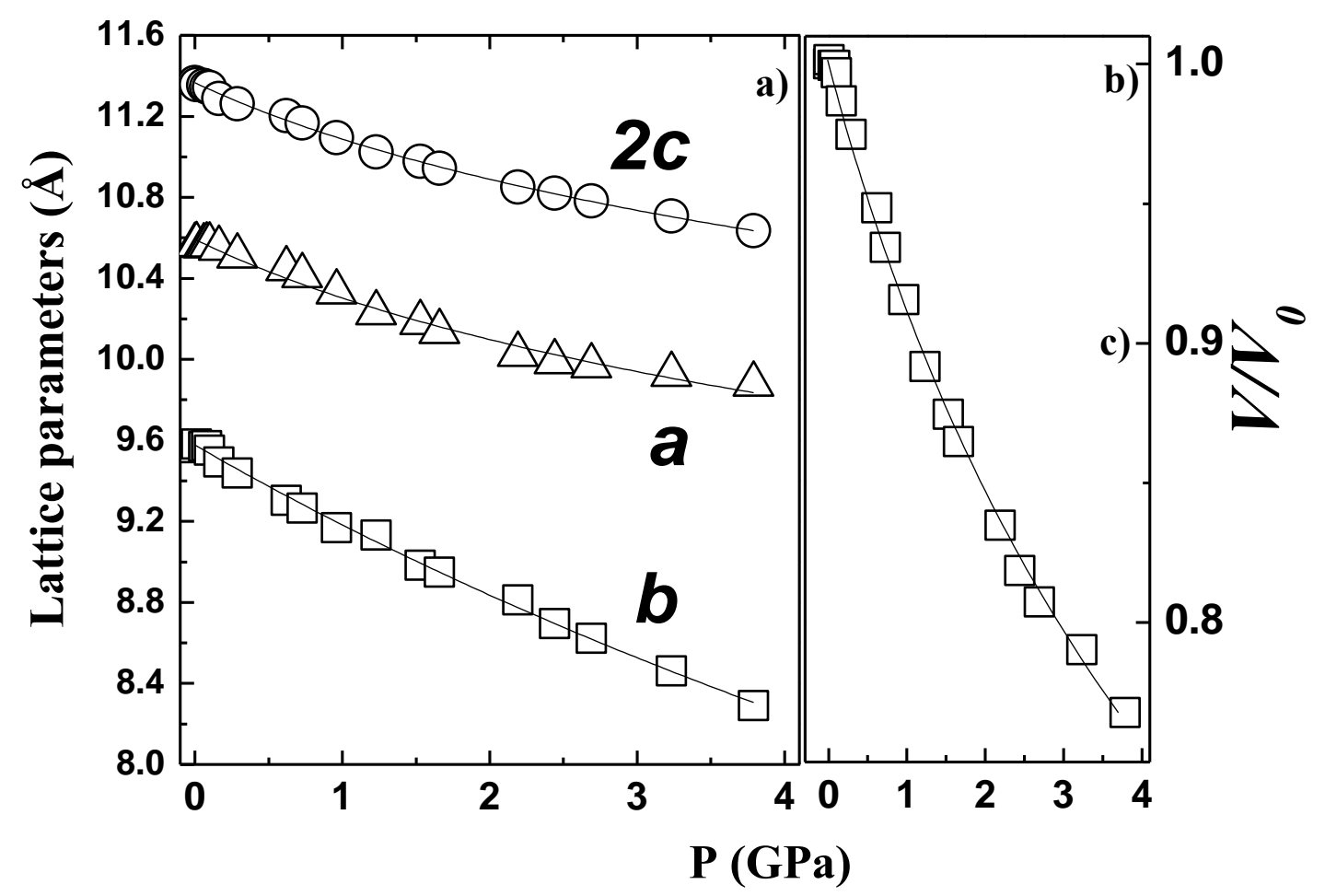

Figure 5. S.E. Kichanov, The polymorphic phase transformations in resorcinol at high pressure 


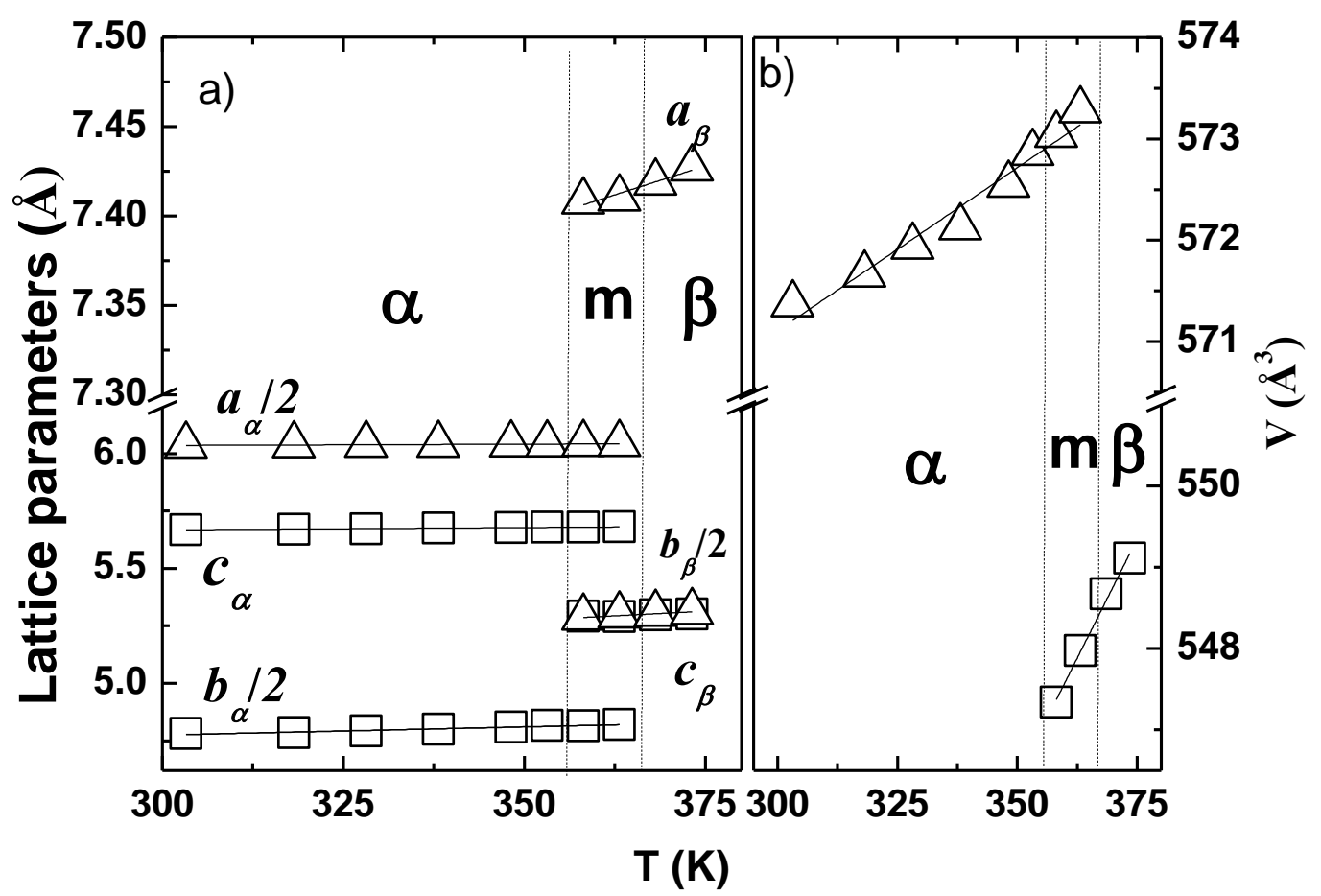

Figure 6. S.E. Kichanov, The polymorphic phase transformations in resorcinol at high pressure 


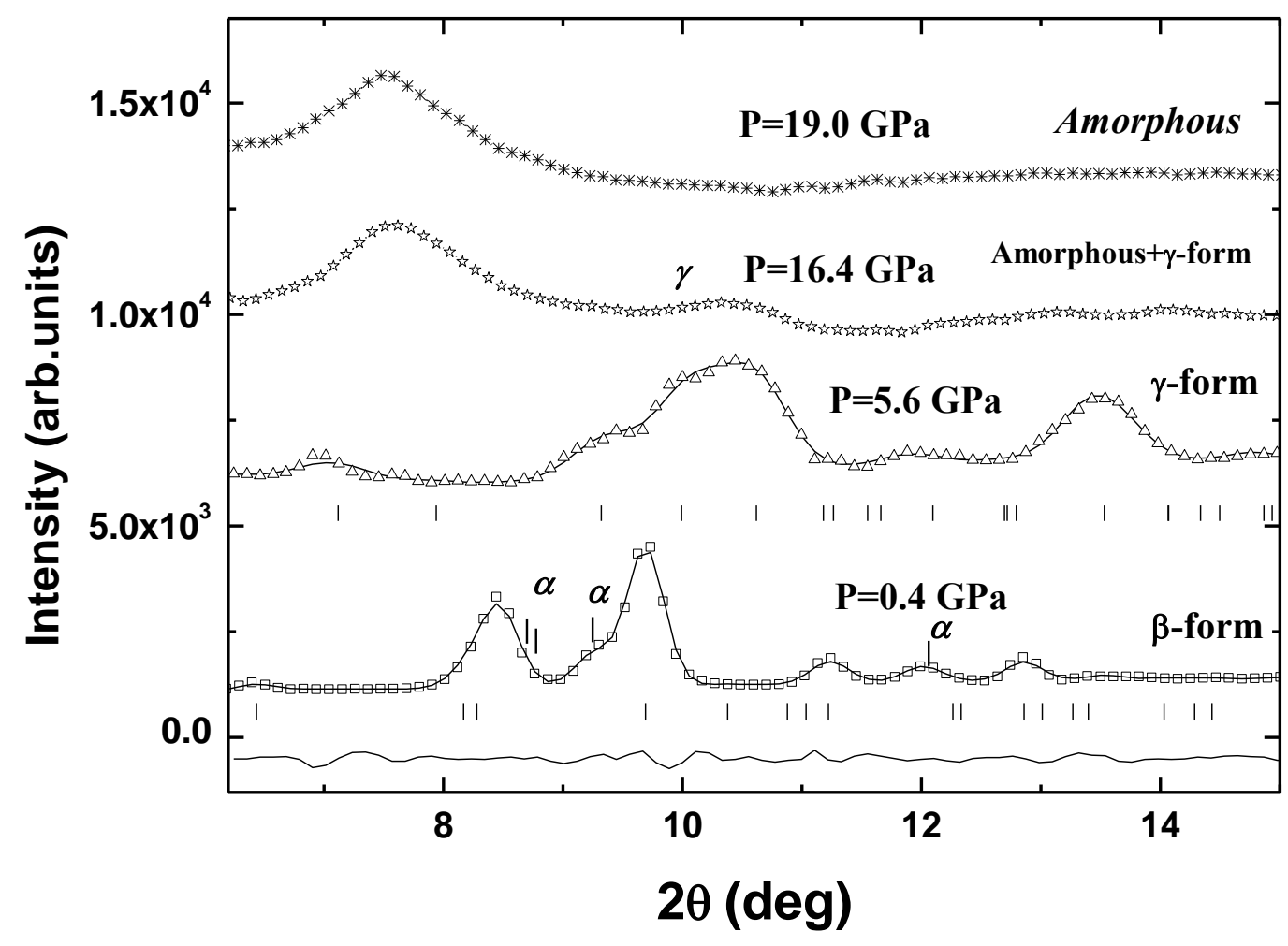

Figure 7. S.E. Kichanov, The polymorphic phase transformations in resorcinol at high pressure 


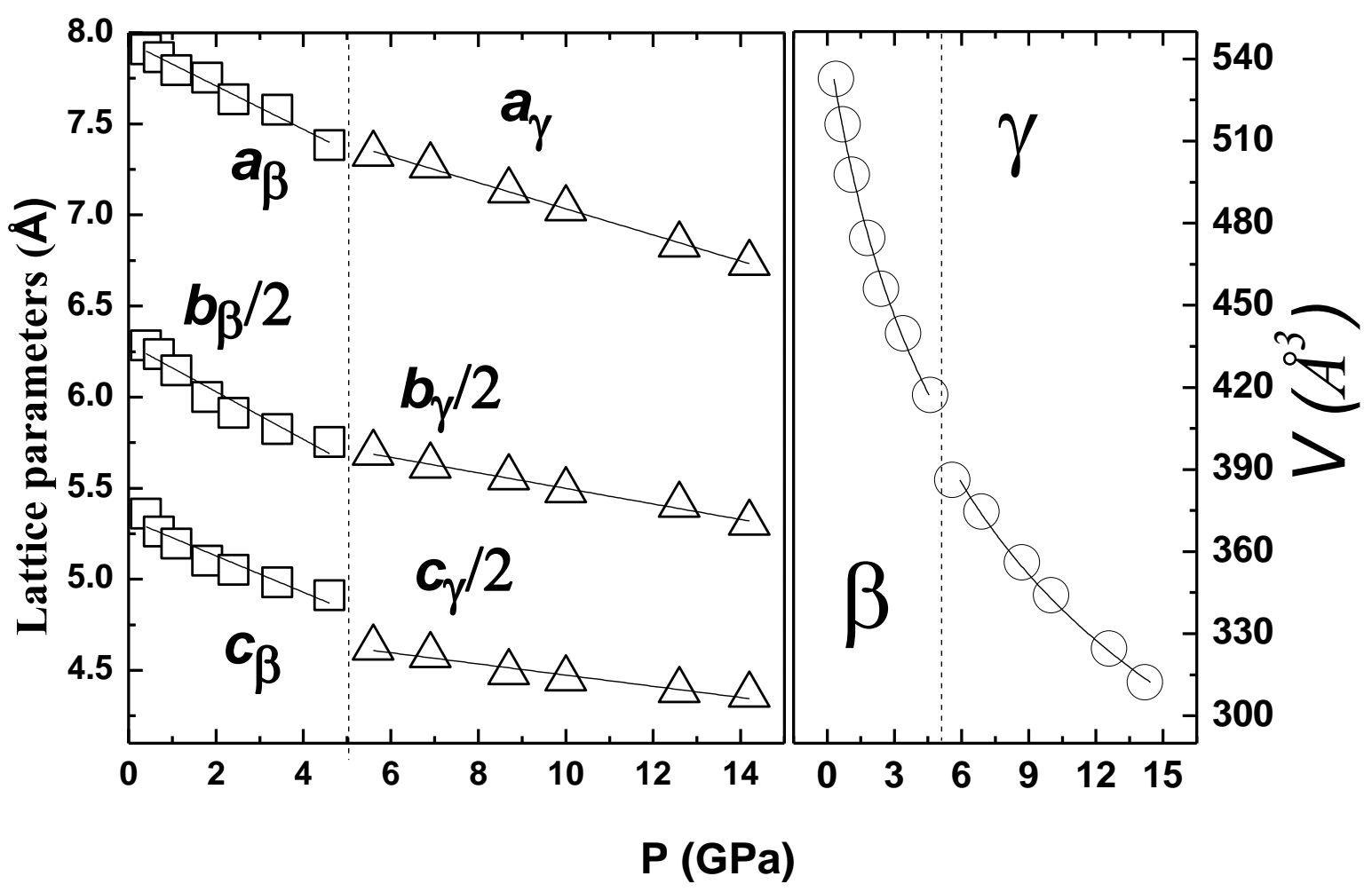

Figure 8. S.E. Kichanov, The polymorphic phase transformations in resorcinol at high pressure 

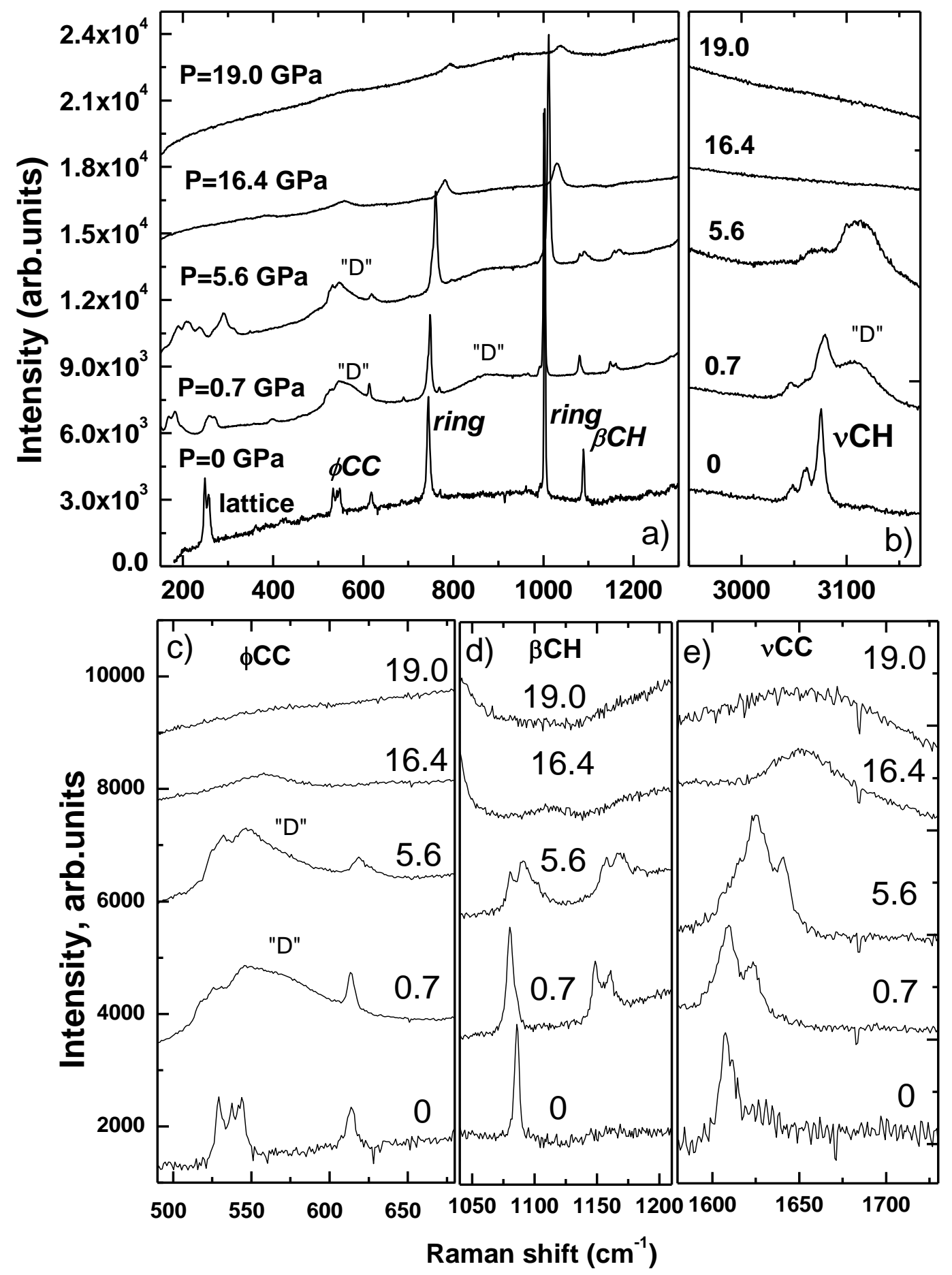

Figure 9. S.E. Kichanov, The polymorphic phase transformations in resorcinol at high pressure 


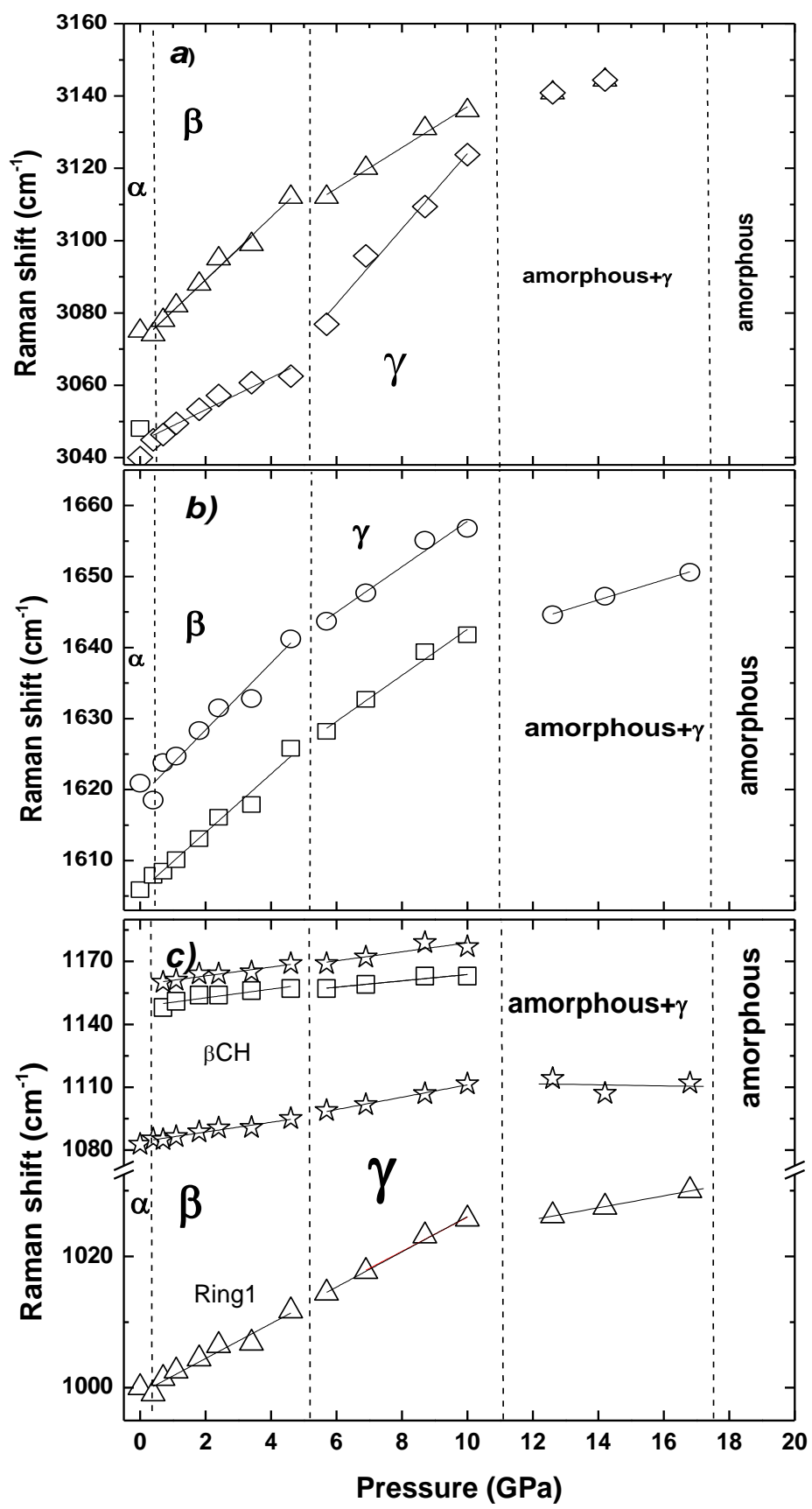

Figure 10. S.E. Kichanov, The polymorphic phase transformations in resorcinol at high pressure 


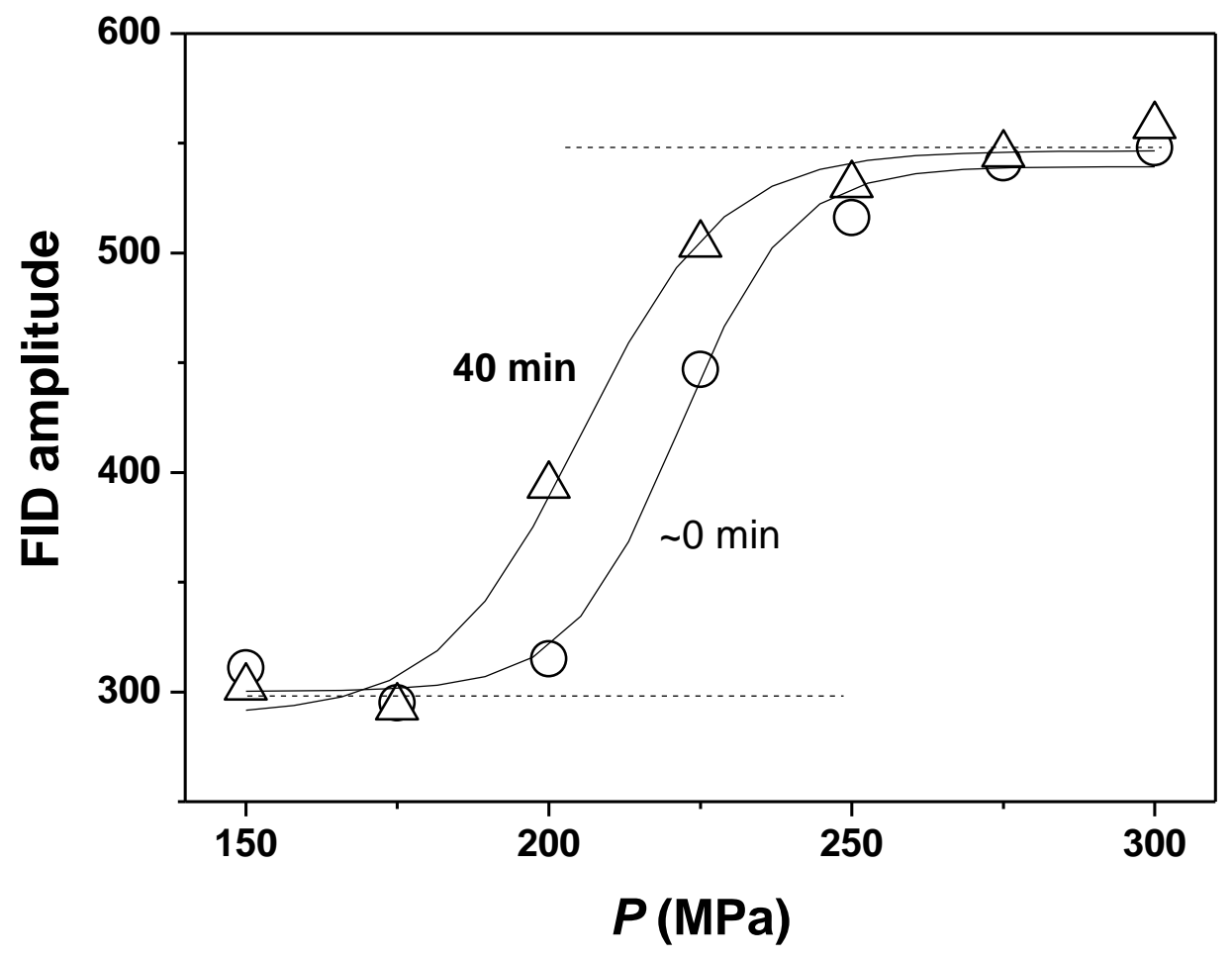

Figure 11. S.E. Kichanov, The polymorphic phase transformations in resorcinol at high pressure 
Journal of Molecular Structure

The polymorphic phase transformations in resorcinol at high pressure

Number of pages is 27.

Number of figures is 11 .

Number of tables is 1 .

Corresponding author:

S.E. Kichanov

E-mail: ekich@nf.jinr.ru

Post address: 141980, Russia, Moscow Region, Dubna, Joliot-Curie str., 6 JINR, Frank Laboratory of Neutron Physics

Tel: +7-49621-63783

Fax: +7-49621-65882 